\title{
Gran universo del lenguaje
}

Great universe of language

DOI: https://doi.org/10.21803/penamer.14.27.459

Arif Asor Andrade Arroyo

https://orcid.org/0000-0003-3249-0991

Elías Jacob Barrios Márquez

https://orcid.org/0000-0003-4548-6326

Ricardo David González Ortíz

https://orcid.org/0000-0002-7806-5440

¿Cómo citar este artículo?

Andrade, A., Barrios, E. \& González, R. (2021). Gran universo del lenguaje. Pensamiento Americano, 14(27), 195-208. DOI: https://doi.org/10.21803/ penamer.14.27.459

\section{Resumen}

Introducción y objetivo: en el presente artículo se analiza la posibilidad de extender la aplicación del concepto de lenguaje, más allá del humano como sujeto y poseedor de este, incluyendo a los animales -no humanos- dentro de su más amplia definición. Método o metodología: primeramente, se hace una revisión de algunos aportes epistemológicos relacionados con la teoría del lenguaje en su dimensión filosófica, psicológica y lingüística. Posteriormente, se revisan los elementos constitutivos de las teorias, procurando identificar aquellas posturas que impliquen una confusión conceptual de los elementos que conforman la totalidad del concepto de lenguaje, para finalmente establecer Conclusiones y resultados: existe una asimilación entre lo que se entiende por lengua y lenguaje, lo cual, ha desembocado en la exclusión de los animales -no humanos- en la categoría de poseedores de lenguaje, cuando de lo que se trata es de la carencia de una lengua estructurada y sistematizada por parte de éstos.

Palabras clave: Lenguaje; Lengua; Pensamiento; Capacidad; Comunicación.

\section{Abstract}

Introduction and objective: in this article we analyze the possibility of extending the application of the concept of language, beyond the human as subject and possessor of this, including animals -not human- within its widest definition. Method or methodology: first, a review is made of some epistemological contributions related to the theory of language in its philosophical, psychological and linguistic dimension. Subsequently, the constitutive elements of the theories are reviewed, seeking to identify those positions that imply a conceptual confusion of the elements that make up the totality of the concept of language, to finally establish conclusions and results: there is an assimilation between what is meant by language and language, which has led to the exclusion of animals -not human- in the category of language holders, when it is a question of the lack of a structured and systematized language on the part of the latter.

Key words: Lenguaje; Lenguaje; Lenguaje; Agility; Comunicación. 
Perfiles

Abogado de la Universidad del Atlántico, Magíster en derecho UNAL, Máster en argumentación jurídica Universidad de Alicante, Máster di secondo livelo in argomentazione giuridica Universidad de Palermo, estudiante de doctorado en derecho Universidad Alcalá de Henares, docente tiempo completo Universidad del Atlántico, líder del semillero de investigación Sapere Aude, programa de Derecho - Facultad de Ciencias Jurídicas- Universidad del Atlántico. Correo: arifandrade@ mail.uniatlantico.edu.co

Estudiante de Derecho, Universidad del Atlántico, joven investigador perteneciente al semillero de investigación Sapere Aude. Correo: ejacobbarrios@mail.uniatlantico. edu.co

Estudiante de Derecho, Universidad del Atlántico, joven investigador perteneciente al semillero de investigación Sapere Aude. Correo: ricardodgonzalez@mail.uniatlantico.edu.co
Arif Asor Andrade Arroyo

Elías Jacob Barrios Márquez

Ricardo David González Ortíz 


\section{Introducción}

El lenguaje a lo largo de la historia ha sido considerado por muchos lingüistas, psicólogos y filósofos del lenguaje como una propiedad meramente humana, porque permite al ser humano distinguirse de los otros animales de la tierra. Ferdinand Saussure entiende por lenguaje a la capacidad que se tiene para constituir una lengua, es decir, un sistema de signos distintos que corresponden a ideas distintas (Saussure, 1945). Benjamín Whorf lo concibe como la herramienta que determina de manera fundamental al pensamiento, principalmente por la estructura lingüística que condiciona la expresión del mismo (Whorf, 1956). En un sentido más radical, Hans Gadamer lo comprende como el verdadero y único centro del ser humano (Gadamer, 1960).

Sea cual fuere su postura o teoría, estos autores coinciden en que sólo se puede hablar del lenguaje a través del lenguaje y por medio de su único poseedor: el ser humano. El pensamiento antropocentrista ha sido fundamental para la elaboración de aquellos paradigmas que encaminan sus esfuerzos a consolidar al ser humano como el dueño del mundo. En ese sentido, las bases filosóficas establecidas por Protágoras van a permear la construcción de todo conocimiento racional y científico, toda vez que, "el hombre es la medida de todas las cosas, de las que son en cuanto son y de las que no son en cuanto no son" (Protágoras (s.f.) citado por Eduardo Tijeras 1965, p. 58).

Este paradigma acerca del lenguaje, es el resultado de una gran confusión en el verdadero significado de los elementos pertenecientes al tridente lenguaje-lengua-pensamiento. Dicha confusión, ha permitido que muchos teóricos a lo largo del tiempo puedan argumentar, en pro de este paradigma, por ejemplo, que los otros animales del mundo no poseen lenguaje porque lenguaje y lengua son lo mismo. Además, como hasta el día de hoy no se ha encontrado evidencia alguna acerca de un conjunto de signos lingüísticos lógicamente estructurados por alguna especie animal distinta a la del ser humano, es imposible concebir siquiera algún esbozo de lenguaje en otro ser que no sea el ser humano.
Ahora, desde la perspectiva de lo que plantea Whorf (1956) sobre la relación pensamiento-lenguaje, el ser humano es el único poseedor del lenguaje, al ser los únicos capaces de generar el pensamiento. Teniendo en cuenta que este último supone una codificación en forma lingüística, luego entonces, pensamiento y lenguaje son prácticamente lo mismo. Por tales motivos, sería casi imposible tratar de hablar acerca del lenguaje en una especie distinta a la nuestra.

Todo argumento que se haga bajo estas condiciones estará contribuyendo al crecimiento de éste gran paradigma, el cual a través del presente trabajo se pretende dilucidar, para que, en ese sentido, se demuestre que no se es "ni los inventores ni los únicos poseedores del lenguaje” (Llinás, 2017, p. 286). Para ello, se enfocarán las siguientes partes:

1. Lenguaje: capacidad y elemento.

2. Lenguaje, lenguay pensamiento.

3. Relación lenguaje-comunicación.

4. Conclusiones.

\section{Lenguaje: capacidad y elemento.}

El lenguaje será entendido de esta manera: Capacidad y Elemento. Lo primero puede decirse que es el conjunto de condiciones y aptitudes naturales del lenguaje, que le son entregadas a todos los poseedores de este, en miras de que estos puedan realizar acciones que, sin el lenguaje serían imposibles de ejecutar. Lo segundo puede ser comprendido como aquel sistema organizado de instrumentos que sirven para materializar y (o) mejorar todas las facultades del lenguaje; esto es grosso modo, la materia con la ópera el gran universo lingüístico.

Es necesario precisar que, estas dos partes no solo encarnan al lenguaje, sino que son per se la carne del lenguaje mismo y es por esta razón, que siempre van a estar unidas de forma imprescindible la una a la otra. 


\subsection{Lenguaje como capacidad.}

El lenguaje como capacidad está compuesto por dos componentes: la interiorización y la capacidad lingüística. La interiorización es aquella parte del lenguaje que permite que la realidad se pueda expresar en forma de abstracciones en la mente. Para Wittgenstein (1921) la relación mundo-lenguaje se da porque tanto el mundo como el lenguaje comparten una misma estructura lógica y porque uno de los fines del lenguaje es describir el estado de las cosas del mundo. La capacidad lingüística, por su parte, es aquella facultad que se tiene bien sea para poder hacer uso del lenguaje como elemento o, en algunas ocasiones, para constituir nuevas manifestaciones de este. En cualquiera de los dos casos, la capacidad lingüística tiene como objetivo principal hacer posible la comunicación.

\subsection{Lenguaje como elemento.}

El lenguaje como elemento está compuesto por todas las manifestaciones del lenguaje, es decir, todas las formas por medio de las cuales el lenguaje cumple su función comunicativa a cabalidad. Dicha función, depende en gran medida de las manifestaciones, puesto que, son estas las que permiten que la comunicación sea distinta entre sí. Estas manifestaciones, se clasifican en inmediatas y mediatas.

Entiéndase a las inmediatas como aquellas manifestaciones que les son naturales al poseedor del lenguaje por sus características fisiológicas y/o genéticas, es decir, que no son adquiridas por el sujeto, sino que son innatas a él. Por su parte, las manifestaciones mediatas son aquellas que no son naturales o propias del poseedor, sino que son el resultado de una elaboración o construcción social entre sujetos de una especie en común, a partir de sus manifestaciones inmediatas o básicas. Dentro de las manifestaciones mediatas, resalta la lengua que se caracteriza por ser meramente humana, producto del uso del lenguaje como capacidad. En ese orden de ideas, la siguiente figura sintetiza de forma estructurada los conceptos que fundamentan el lenguaje.

\subsection{Interacciones del lenguaje.}

Para poder entender el gran universo del lenguaje, debe saberse primero que el lenguaje cumple con sus funciones (representativa y comunicativa) a través de

\section{Figura 1}

Lenguaje

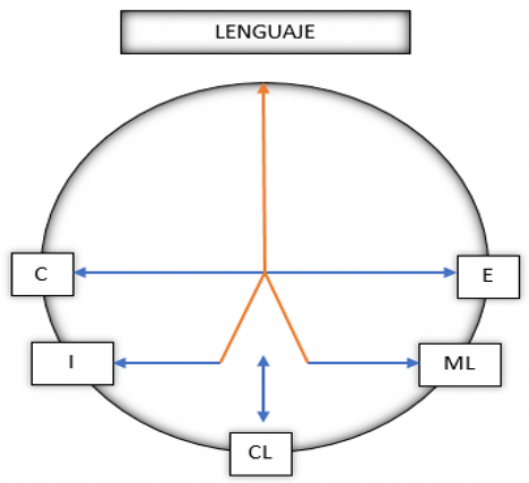

Nota: Siendo C, Capacidad; E, Elemento; I, Interiorización; ML, Manifestaciones lingüísticas y; CL, Capacidad Lingüística. Fuente: Elaboración de los autores.

las interacciones que se dan constantemente entre las piezas que lo componen. La interacción fundamental, es decir, aquella que en sí misma comprende todo el lenguaje, es la interacción capacidad-elemento. Capacidad que se entiende como aquella facultad inmanente de todo ser vivo, y elemento que se puede comprender como aquel instrumento por medio del cual la capacidad se materializa. Por tal motivo, es necesario hablar entonces, de las interacciones que se dan entre dichos componentes.

Las interacciones sirven a un orden tripartito de relación mutua entre cada componente: la primera interacción se da entre interiorización-manifestaciones lingüísticas; la segunda interacción es aquella que se da entre capacidad lingüística-manifestaciones lingüísticas y; en la tercera interacción se encuentra la relación interiorización-capacidad lingüística. La siguiente figura pretende ejemplificar la interacción mutua y tripartita que se da entre los componentes mencionados. 


\subsubsection{Interiorización-manifestaciones lingüísticas.}

Esta interacción se da a partir de la necesidad de las partes. En primer lugar, surge la necesidad que tiene la interiorización de poder aumentar y (o) mejorar

\section{Figura 2}

\section{Interacciones del lenguaje}

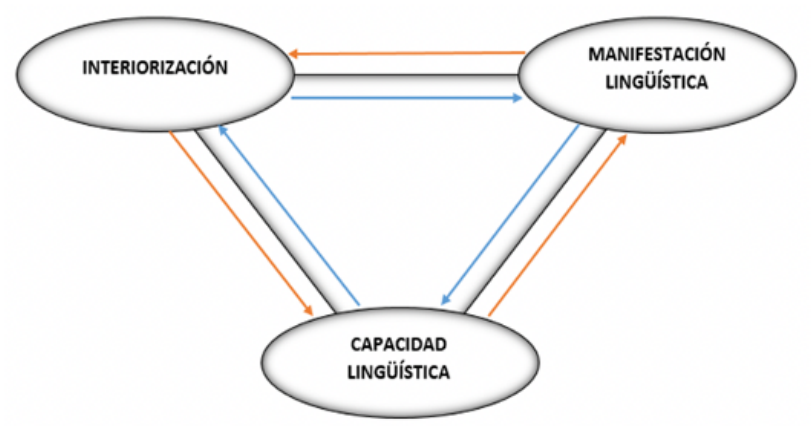

Fuente: elaboración de los autores.

su efectividad. El proceso de interiorización es más efectivo cuando la conexión entre la realidad y los universales, se hace más rápida o más fácil de generar. La efectividad se mide en grados, los cuales pueden ser mínimos, medios y máximos.

El grado mínimo de interiorización es aquel en el cual el lenguaje, mediante los sentidos, permite que un poseedor de él pueda hacerse una imagen mental (universal) de lo que percibió por cualquiera de estos. Se denomina como mínimo porque para el poseedor del lenguaje es a veces imposible distinguir o diferenciar entre algunos elementos de la realidad, puesto que, siempre necesita de la presencia de ella para poder hacerse una imagen de la misma. Verbigracia de lo anterior: los perros, para hacerse una imagen mental de su comida, necesitan la presencia de ésta, a fin de que, pueda percibir su existencia a través de sus sentidos (olfato o vista) y, para que, pueda tener una imagen de ella en su mente por intermedio del lenguaje.

Por su parte, el grado medio de interiorización es aquel que para darse necesita de signos lingüísticos, a saber, la entidad psíquica compuesta por dos caras o elementos: el concepto y la imagen acústica, que hace posible representar completamente un evento comu- nicativo en sus propios términos (Saussure, 1945).

Este grado de interiorización facilita la distinción o diferenciación de los elementos de la realidad, al darle una imagen acústica (significado) a cada concepto (significante). Es posible darle una estructura lógica al universal aue se ha creado en nuestro "microcosmos" Figura 3

\section{Manifestaciones lingüisticas}

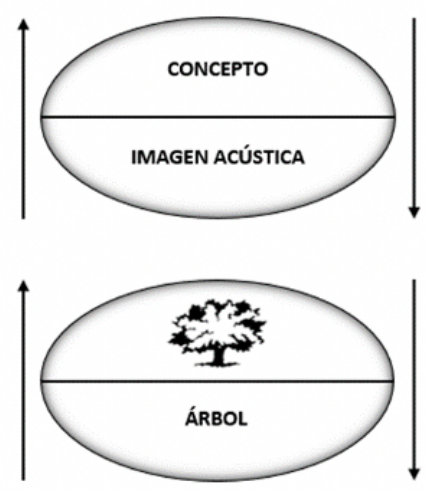

Fuente: (Saussure, 1945, P. 92).

de tal forma que no solo se puede ver la abstracción en la mente, sino que además se puede ir caracterizando, llenándola de atributos, esto es: de cualidades que la hagan distinta.

En una primera instancia sólo será la imagen acústica con la cual se refiere al concepto, que permita esa distinción. Pero a medida que mejore la interacción entre la capacidad lingüística y las manifestaciones lingüísticas, en la cual se desarrollan todo tipo de signos, símbolos y señales, se podrán atribuir cualidades que distinguen con mayor fuerza dicho concepto o significante. Todo esto en pro del efectivo proceso de interiorización que se da en el lenguaje como capacidad.

Por último, el grado máximo de interiorización es aquel en el cual la conexión entre abstracción y realidad es tan efectiva que ya la abstracción en sí misma no necesita de la realidad. Esto por la utilización de signos lingüísticos que permiten la creación y estructuración del pensamiento, los cuales hacen que las imágenes acústicas o significados puedan crear y ser en su totalidad sus propios significantes. De esta manera, ya no 
solo describen el estado de las cosas del mundo tal y como dijo Wittgenstein, sino que ahora le dan posibilidad al poseedor del lenguaje de poder crear y describir su propio mundo, así como también sus propias cosas.

Muestra de lo anterior es que, existen imágenes acústicas que representan a conceptos que no están materialmente en nuestra realidad, sino que son el resultado del estado o grado máximo de interiorización. Un ejemplo de esto podrían ser los libros de ficción o fantasía, en los que se describen en mayoría conceptos o significantes que, si bien cuentan con una imagen acústica o significado, físicamente no hacen parte de la realidad. Este grado máximo, además, le permite al poseedor del lenguaje gozar de imaginación, la cual se puede decir que es la facultad para representar mentalmente sucesos, historias o imágenes de cosas que no existen en la realidad o que son o fueron reales, pero no están presentes (Sánchez, 1921).

En segundo lugar, se encuentra la necesidad de que las manifestaciones lingüísticas puedan facilitar la comunicación a través de la interiorización que, para el caso, permite que el mensaje que se emite pueda ser expresado en forma de abstracción en la mente del receptor, (siempre y cuando éste conozca previamente la referencia). Las manifestaciones lingüísticas cumplen con la función comunicativa del lenguaje, siempre que la interiorización sea utilizada como instrumento de la misma. De no existir la representación de conceptos o significantes, la existencia de imágenes acústicas o significados no tendría sentido, puesto que, el receptor sería incapaz de entender el contenido del mensaje enviado por el emisor. De esta forma, toda manifestación lingüística sería inútil a la hora de comunicar y, en ese sentido, el lenguaje sería ajeno a su función comunicativa.

\subsubsection{Capacidad lingüística-manifestaciones lin-} güísticas.

Nuevamente se está en presencia de una relación de necesidad mutua. En un primer punto, está la necesidad de la capacidad lingüística que es apenas lógica, puesto que, de no existir manifestaciones lingüísticas, la facultad de ponerlas en funcionamiento (C.L) no tendría razón de ser. Esto es casi similar al siguiente ejemplo: el músico que cuenta con los conocimientos necesarios para tocar su instrumento, pero carece del mismo para materializar todo lo que en abstracto sabe de éste. Lo mismo pasa con la necesidad de las manifestaciones lingüísticas, pues por definición, son el instrumento por medio del cual la capacidad se hace efectiva para cumplir así con la función comunicativa del lenguaje.

Siguiendo con el ejemplo, imaginen que esta vez sí hay instrumento, pero nadie tiene la más mínima idea de cómo se toca, es decir, no hay ningún músico, ni nadie que tenga la capacidad para utilizarlo, de tal forma que, este pueda cumplir a cabalidad con su función. De cualquier manera, es evidente la necesidad mutua de las partes. Ahora bien, también es de vital importancia precisar que, así como las manifestaciones lingüísticas tienen más de una forma (inmediatas y mediatas), la capacidad lingüística ejerce más de una función. Por tales motivos, resulta necesario decir que en cada una de sus partes específicas C.L Y M.L interactúan de una forma distinta.

En una primera instancia, se da la interacción entre las manifestaciones inmediatas y el uso de las mismas por parte de la capacidad lingüística, la cual se limita a utilizar la estructura biológica del poseedor del lenguaje para hacer efectiva la función comunicativa. Señales táctiles, químicas, visuales y auditivas, entran en funcionamiento precisamente como consecuencia de la C.L que, de cierta forma y siguiendo con el ejemplo, toca la música que ya está escrita genéticamente en las partituras de todo ser lingüístico (poseedor del lenguaje).

En una segunda instancia, se encuentra la interacción que se da entre las manifestaciones mediatas y la capacidad lingüística, en función de uso adquirido, es decir, que requiere de un proceso de aprendizaje para su ejecución. Esta relación nace a partir de la C.L que no se limita a utilizar una manifestación inmediata existente, sino que, constituye de cero manifestaciones lingüísticas distintas de las mencionadas. Lo expuesto 
no solo es en aras de mejorar la función comunicativa del lenguaje, sino además de permitir la expresión del pensamiento. En términos de Chomsky, se trata del verdadero objetivo del lenguaje, en tanto dicha expresión, "es una necesidad humana a la cual responde la aparición del lenguaje” (Barón \& Müller, 2014, p.420).

Para efectos de comprender la terminología que se busca esclarecer, debe tenerse en cuenta que Chomsky, al igual que otros autores, describe al lenguaje en palabras que corresponden a la definición de la lengua. Teniendo en cuenta los presupuestos planteados, será la lengua la que tiene por objetivo la expresión del pensamiento.

Siguiendo con el ejemplo que se ha venido trabajando, imagínese que, en esta ocasión, el músico crea su propio instrumento, el cual debe aprender a utilizar, para que, en algún sentido se logre comunicar musicalmente con todos aquellos que aprendan las reglas y el uso de este.

\subsubsection{Interiorización-capacidad lingüística.}

En esta interacción, las partes por pertenecer a una misma esfera del lenguaje (como capacidad), no se relacionan directamente, sino que lo hacen como consecuencia de las necesidades de las M.L (manifestaciones lingüísticas). Puesto que, para cumplir con su función (esencial) requieren tanto de la capacidad lingüística como de la interiorización, en la medida en que, de no ser por ellas, las manifestaciones no podrían ni expresarse de forma abstracta en la mente, ni mucho menos ser útiles en la comunicación. Para entender lo anterior, se refleja la siguiente figura:

En el lenguaje, las manifestaciones lingüísticas son como la pieza verde del medio, porque necesita claramente de otras piezas para poder completarse. Esto último (que en principio puede verse como un defecto), es lo que la hace tan importante, ya que, conecta a piezas del lenguaje como la interiorización y la capacidad lingüística que, por sus características propias no se ven en la necesidad de unirse la una a la otra -tal y como sucede en la figura con la pieza azul (izquierda) y ama-

\section{Figura 4}

Capacidad lingüistica.

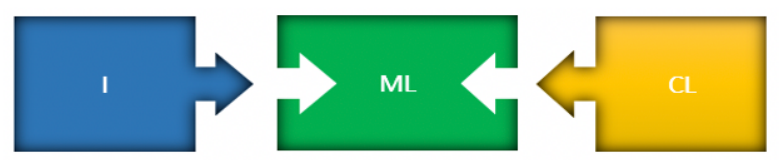

Nota: Siendo: I, Interiorización; M.L, Manifestaciones Lingüísticas; C.L, Capacidad Lingüística.

Fuente: Elaboración de los autores.

rilla (derecha)-. No obstante, lo anterior, sí lo hacen en la medida en que solventan un vacío natural y propio de las M.L, todo esto en aras de armar correctamente el gran rompecabezas del lenguaje.

\section{Lenguaje, lengua y pensamiento.}

Una de las principales razones por las cuales la comunidad científica (en mayoría), ha excluido a los otros animales de la tierra del estudio del lenguaje, es la aparente incapacidad de estos para aprender y hacer uso del mismo. Como se dijo en el capítulo anterior, existe una confusión entre los términos pertenecientes al tridente lenguaje-lengua-pensamiento, la cual ha permitido que, a través de los años, se argumente que son los seres humanos los únicos poseedores del lenguaje, ya sea porque son los únicos poseedores de la lengua o, porque son los únicos capaces de generar pensamiento.

Por los motivos antes mencionados, es absolutamente necesario explicar las diferencias entre el lenguaje, la lengua y el pensamiento, en aras de lograr demostrar que cada elemento cuenta con sus propias cualidades y, por consiguiente, no deben ser considerados como lo mismo.

\subsection{Lengua.}

Para entender la lengua tal y como aquí se tratará, se utilizará el siguiente ejemplo: imaginen que un grupo de músicos prestigiosos decide crear un nuevo instrumento, con el objetivo de mejorar la calidad musical de todos los miembros del instituto al que pertenecen. Para ello, se dan a la tarea de I. Realizar un estudio pro- 
fundo de sus cualidades técnicas; II. Determinar cuál debe ser la forma del instrumento, (en aras de que el mismo pueda compenetrarse con ellos a la perfección) y; III. Elaborar un manual para la correcta utilización de este. Una vez terminado, lo perfeccionan de forma conjunta y logran así su cometido.

La lengua por ser una manifestación lingüística mediata es precisamente como el instrumento del ejemplo, puesto que, nace a partir de un proceso de construcción social entre miembros de un "instituto" o especie en común. Todo ello, con el objetivo de mejorar la calidad musical o comunicativa del lenguaje, lo cual sólo se hace posible al seguir los pasos ya planteados, a saber: realizar un estudio profundo de nuestras cualidades técnicas o biológicas; determinar la forma que va a tomar la lengua en nuestras realidades y; elaborar, finalmente, un manual que sirva de guía para su correcta utilización, lo que, al igual que en los pasos anteriores se deberá perfeccionar de forma conjunta, hasta alcanzar el cometido.

De la lengua es importante mencionar que esta no es autónoma, a razón de que, siempre necesita de otros elementos del lenguaje para desarrollarse, puntualmente, de la capacidad lingüística y la interiorización, las cuales permiten, respectivamente: que la lengua entre en funcionamiento $\mathrm{y}$, asimismo, que esta pueda conectarse con la mente del poseedor. Siguiendo con la lógica del ejemplo, la capacidad lingüística sería como aquella facultad que tiene el músico (poseedor humano del lenguaje) de poder utilizar de forma correcta a la lengua, para que la misma pueda generar música o comunicación. Por su parte, la interiorización sería aquella herramienta que permite que la música (lengua) se expresa en la mente de aquellos que la puedan escuchar.

Otro aspecto de la lengua que debe ser explicado es el habla que, bajo los postulados de Saussure (1945), se define como:

Un acto individual de voluntad y de inteligencia en el cual conviene distinguir entre: 1. las combinaciones por las que el sujeto hablante utiliza el código de la len- gua con miras a expresar su pensamiento personal; 2 . el mecanismo psicofísico que le permite exteriorizar esas combinaciones (p. 41).

El habla pertenece exclusivamente a la esfera de la lengua, esto significa que, quien puede hablar ha adquirido la lengua. Ahora bien, esto no quiere decir que por el simple hecho de adquirirla ya puede ser hablada, puesto que, el habla necesita de ciertas condiciones para poder exteriorizar la lengua. Si se entiende a esta última como un instrumento, se dirá que la primera (el habla) es como la amplificación que permite que la música generada por la lengua pueda ser escuchada por los demás músicos de nuestra especie. Es por esto que, quienes carezcan de tal estructura amplificadora, a pesar de haber adquirido la lengua, no podrán hablarla.

No obstante, es menester aclarar que, el habla no es ni el único, ni el más importante medio de exteriorización que tiene la lengua, pues la escritura es desde lo que aquí se plantea, el centro de todas las funciones de la lengua en el lenguaje. Aunque la más común de todas las formas de exteriorización sea el habla, lo que, en ese sentido, permite que sea la más conocida.

La lengua, además de distinguirse por su proceso de creación (punto que es totalmente imposible en las manifestaciones inmediatas, puesto que, son biológicamente establecidas), también lo hace por sus utilidades, debido a que ésta a diferencia de otras manifestaciones, no tiene como único fin comunicar, sino además multiplicar y expresar el pensamiento. En ese cometido, es una consecuencia irremediable de su propia naturaleza, debido a que, es precisamente el pensamiento el componente principal de la lengua. Retomando el ejemplo desarrollado, es la madera fina que los músicos o poseedores del lenguaje utilizaron por intermedio de la capacidad lingüística para poder materializar su creación. Es por esta razón, que a la lengua se le da muy bien el papel de instrumento más idóneo de producción de pensamiento.

Por este y otros motivos, la lengua es única en su especie y para todos los humanos, es tan importante como la vida misma. Sin embargo, no por ello es lo 
único en este gran universo del lenguaje, considerando que, el lenguaje propiamente dicho se encuentra por fuera de todos los elementos que lo componen. Ni la lengua es todo en el lenguaje, ni el hombre es el único en su universo, pues la presencia de elementos propios del mismo, o la ejecución de acciones que solo pueden realizarse a través de él, en cualquier ser, sí da por sentada la existencia del lenguaje en éste. Dicho esto, pensar que la lengua es todo el lenguaje en general, es tan descabellado como afirmar que un solo instrumento contiene por sí mismo a toda la música del mundo.

\subsection{Pensamiento.}

Mucho se ha dicho acerca del pensamiento y su relación con el lenguaje. Algunos autores como Benjamín Whorf creen que el lenguaje determina de tal forma al pensamiento que, si el primero no existiera, el segundo muy seguramente tampoco lo haría, debido a que el lenguaje no es simplemente un instrumento reproductor de ideas, sino que es en sí mismo el verdadero formador de las mismas (Whorf, 1956). Otros teóricos como Lev Vygotsky (1934) si bien consideran que tal determinación sí existe, prefieren inclinarla al otro lado de la balanza, es decir, contrario sensu de lo que manifestaba Whorf, Vygotsky creía que el lenguaje sólo adquiere importancia, en la medida en que el mismo "está ligado al pensamiento e iluminado por él” (p. 168).

Ahora bien, pese a que estas posturas acerca del tema no están tan alejadas de la idea que se pretende desarrollar, en aras de diferenciar el pensamiento y el lenguaje, lo cierto es que es menester definir en primera medida que es el pensamiento desde la perspectiva del presente trabajo. El pensamiento puede ser comprendido como aquella actividad cognitiva de reflexión, esto es, de atención detenida hacia algo o alguien en aras de entenderlo. Dicha actividad puede ser lingüística o no-lingüística. Es lingüística cuando necesita para su ejecución de contenedores psíquicos llamados palabras; y es no-lingüística cuando no requiere o no ha adquirido tales "contenedores" para su desarrollo.

Con base en lo anterior se pueden evidenciar dos aspectos fundamentales, el primero es que efectivamente sí existe una relación entre el lenguaje y el pensamiento, y lo segundo es que aunque exista tal relación no siempre va ser indispensable para el pensamiento. Siguiendo ese orden ideas, es necesario precisar de qué forma en específico se relacionan el lenguaje y pensamiento. Para ello se hará uso de la siguiente figura que pretende ejemplificar lo anterior y sirve además de base para explicar lo que, acto seguido se expondrá:

\section{Figura 5}

El lenguaje y el pensamiento

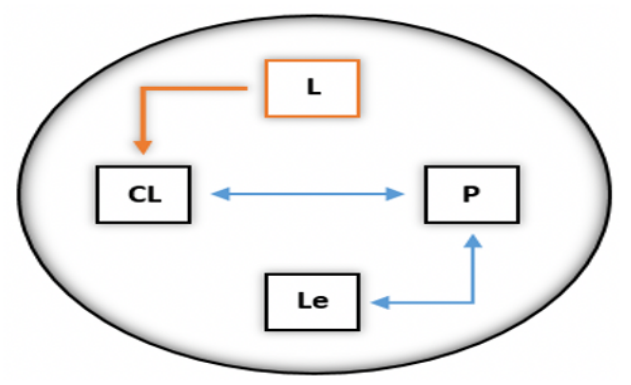

Nota: Siendo: L, Lenguaje; CL, Capacidad Lingüística; Le, Lengua; P, Pensamiento.

Fuente: elaboración de los autores.

Como se puede observar, la relación del lenguaje y el pensamiento no es directa sino indirecta, ya que es a través de la lengua, que entran en contacto, la cual a su vez es el resultado de la unión entre la capacidad lingüística y el pensamiento no-lingüístico, como se dijo anteriormente. Así las cosas, pese a que sí están relacionados no están totalmente unidos, todo esto en razón a la naturaleza indirecta de su relación, en la cual la lengua siempre juega un papel importantísimo.

De lo anterior surge, el hecho de que la lengua sea como aquella abeja que extrae el polen del pensamiento a través de los aguijones de la palabra. Se alimenta de él y va y lo reparte a todas las futuras flores, del gran campo de nuestra especie. Por lo que se dice que, cuando crece la lengua crece el pensamiento y viceversa. Esta es una relación a la que, sin duda alguna, se deben todos y cada uno de los logros humanos conseguidos y por alcanzar. 
Ahora bien, el pensamiento también ha nutrido a la lengua y la ayuda a mejorar. En mérito de lo expuesto, Piaget (1977) afirma que el pensamiento "se limita a transformarla profundamente ayudándole a alcanzar sus formas de equilibrio mediante una esquematización más avanzada y una abstracción más móvil” (p. 115). Esto a raíz de que, como se dijo ya, el pensamiento es la materia prima del producto conocido como lengua.

Ellos (la lengua y el pensamiento) sí que interactúan directamente no como el caso del lenguaje que, si bien contiene a la lengua, no es la lengua y por tal motivo no se relaciona de la misma forma con el pensamiento. Tal y como se ve en la figura nunca entran en contacto, sino a través de unas intermediarias llamadas lengua y capacidad lingüística, las cuales, si bien pertenecen al lenguaje, en sí mismas no lo son. Con todo esto, se debe entender que el lenguaje es el género de los géneros y no una especie de las especies, pues está por fuera de sus elementos y estos últimos siempre están dentro de él.

Por las razones mencionadas, creer que los otros animales de la tierra no tienen lenguaje a raíz de su falta de pensamiento, sería tan desacertado como decir que un hombre de color no es un ser humano, por el simple de hecho de no tener los ojos verdes. En ese sentido, se necesita ver al pensamiento como aquel color que toma el lenguaje en los seres humanos, el cual lo hace un tanto distintos, pero por sí mismo no puede hacer que se sean los únicos poseedores de éste (el lenguaje), pues como se ha dicho los otros animales también lo son, aunque no tengan pensamiento (o quizás si posean uno, pero distinto).

De esta forma, así como el hombre del ejemplo es un ser humano, a pesar de no tener los ojos verdes, los animales de la misma manera, pese a no tener pensamiento son sin duda alguna, poseedores del lenguaje. Y todo porque, lo que hace la distinción es el color y no el ojo, a saber, el pensamiento y no el lenguaje, que como se ha visto no pertenece exclusivamente al ser humano.

\section{Relación lenguaje-comunicación.}

Desde hace ya dos capítulos se ha mencionado de formareiteradaqueel serhumano sonlosúnicosposeedores del lenguaje, porque a aquello que comúnmente se le llama lenguaje, o es lengua o es pensamiento, pero en definitiva no es verdadera, ni completamente lenguaje en propiedad. Se dijo también que el lenguaje era como un gran universo al que pertenecían muchos planetas: algunos grandes, otros pequeños, algunos similares, otros diferentes, pero que en general todos eran parte o producto del mismo. Todo esto se dijo, con el ánimo de poder diferenciar el lenguaje (siendo tan grande y único como es), de otros elementos que son o una especie de su género, o, un producto de su especie.

Ahora bien, en el presente capítulo, las cosas van a ser un poco distintas, ya que no se va a hablar acerca de los "planetas" del lenguaje, sino de las funciones "universales" de éste, específicamente de una de ellas: la comunicación.

\subsection{Perspectivas de la comunicación.}

La comunicación puede ser entendida desde dos puntos de vista: uno interno y otro externo. Desde el punto de vista interno, la comunicación es aquel producto del lenguaje, generado de forma natural por los elementos que lo conforman. Desde el punto de vista externo, es aquel instrumento mediador entre el lenguaje y el objetivo máximo de éste.

La comunicación desde lo interno está formada esencialmente por el lenguaje, tanto así que podría decirse que "la materia prima con que opera la comunicación es el lenguaje” (Trillos, 2017, p. 300). Esto en tanto son los elementos de este último, a través de las interacciones lingüísticas, quienes permiten que la comunicación exista y cumpla con su único objetivo: servir al lenguaje. Para entender lo antes mencionado imaginen lo siguiente: un buen día cierto pintor, al necesitar de un color nuevo para poder terminar su obra, decidió mezclar los únicos colores que tenía. Estos últimos, para sorpresa del pintor, originaron un color nunca antes visto, el cual permitió cumplir con el propósito planteado.

El lenguaje, entendido a partir del ejemplo, es como 
aquel pintor que utiliza sus dos colores: capacidad y elemento para poder crear la comunicación, la cual como ya se dijo, está conformada sustancialmente por los componentes o colores "primarios" del lenguaje. Frente a tales preceptos, son estos los que permiten la existencia o creación del nuevo color para el lenguaje.

Desde lo externo, la comunicación es aquella forma (o función) mediante la cual el lenguaje alcanza su objetivo principal, siendo este el unir a todos, miembros del gran reino animal. Tomando de base el ejemplo ya expuesto, la comunicación sería como el pincel que utiliza el pintor para poder cumplir con su objetivo, el que, para el caso consiste en lograr unir a los poseedores del lenguaje de la misma especie (unión homogénea), así como a los poseedores del lenguaje de especies distintas entre sí (unión heterogénea). En este sentido, comunicar significa ayudar a unir, en la medida en que unir es el gran objetivo de todo el universo del lenguaje. La siguiente figura ejemplifica de forma estructurada lo antedicho.

\section{Figura 6}

\section{Comunicación interna y externa}

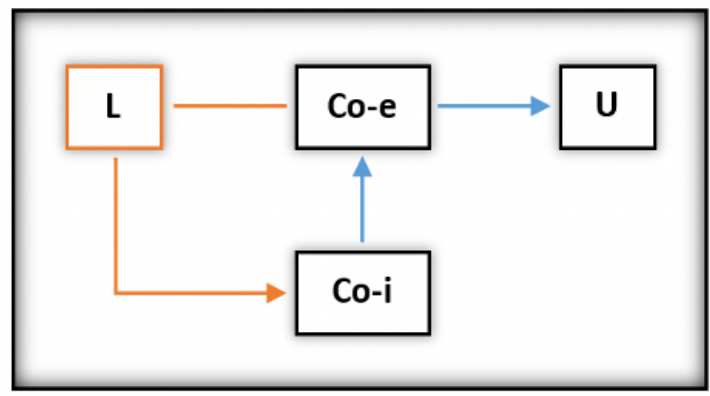

Nota: Siendo: L, Lenguaje; Co-i, Comunicación interna; Co-e, Comunicación externa; U, Unificación. Fuente: elaboración de los autores.

En conclusión, la comunicación desde sus dos perspectivas puede ser comprendida como aquella herramienta producida por el lenguaje, en aras de poder cumplir con su propósito elemental.

\subsection{Formas de comunicación.}

Como se planteó en una primera instancia, la co- municación es ante todo un producto del lenguaje, por lo cual todo poseedor del lenguaje está en capacidad de comunicar. No obstante, dicha comunicación va a variar según las características propias de cada poseedor. Esto significa que la comunicación va a tomar distintas formas según el poseedor del lenguaje que la genere. Para ejemplificar lo antes mencionado, imaginen que: el lenguaje es como un carpintero que para poder sobrevivir necesita atravesar un río, pero no puede hacerlo por sí solo, ya que las aguas de este son muy profundas. Por tales motivos, crea con ayuda de las herramientas y materiales que posee, una barca, la cual le permite ahora cruzar el río cuantas veces quiera.

El lenguaje de la misma forma que el carpintero, crea a la comunicación con el fin de que esta le permita sobrevivir, al cumplir con su objetivo principal. De igual manera, utiliza constantemente las herramientas y materiales propios de cada poseedor del lenguaje, para que este pueda comunicarse, según el medio creado a partir de sus características naturales.

Toda forma de comunicación se diferencia entre sí por la clase de manifestación lingüística que esta posea. Como se explicó anteriormente, las manifestaciones se clasifican en: inmediatas y mediatas, siendo las primeras aquellas que son propias de cada poseedor, y que se generan según sus características biológicas; $\mathrm{y}$ las últimas, aquellas que tienen un carácter convencional, a saber, que son el producto de varios procesos llevados a cabo por miembros de una especie a lo largo del tiempo.

Las formas de comunicación en casi todos los casos basan su funcionamiento en una manifestación lingüística inmediata, que puede ser desde una señal química, hasta una señal visual o auditiva. Lo cierto es que esta es la regla general en casi todas las formas de comunicación. Ahora bien, existen excepciones tales como las manifestaciones mediatas, dentro de la cual resalta la lengua. De esta manera, van a ver formas de comunicación inmediatas y mediatas, las que recibirán su nombre según la manifestación lingüística en la que se basen.

Por lo anterior expuesto, es evidente que la comunicación se genera de manera diferente. Hay formas 
de comunicación que, siguiendo con el ejemplo, son como un yate: totalmente sofisticado, rápido, y en proporción mucho más grande que una barca, pero no por eso va a ser el único y exclusivo medio, a través del cual el lenguaje alcanza su propósito, debido a que, existen formas de comunicación que, si bien pueden parecer menos efectivas que un yate o un buque, de igual forma sirven al lenguaje y a sus correspondientes poseedores. Así las cosas, pese a que existen distintas formas de comunicación, todas ellas (en la medida de sus posibilidades) prestan un gran servicio al lenguaje.

\subsection{Paradigmas acerca de la comunicación.}

La comunicación a lo largo de la historia ha sido tratada por un sin número de autores. Las posiciones con respecto a la misma varían cada tanto, no obstante, se podría decir que en general existen planteamientos mayoritariamente aceptados por la comunidad científica experta en el tema.

La comunicación según muchos de estos expertos, es una cualidad exclusivamente humana. Por ello, al igual que con el lenguaje, se ha pretendido excluir a los otros animales de la tierra, afirmando por el ejemplo que: "la comunicación no mediatizada por el lenguaje o por algún otro sistema de signos o medios, sólo puede ser, como se observa en el reino animal, del tipo más primitivo y dentro de los más reducidos límites" (Vygotsky, 1934, p. 8). Vygotsky, al igual que otros autores, describe el lenguaje en los mismos términos en los que se encuadra la lengua. En ese sentido, para este apartado la palabra "lenguaje" deberá sustituirse por la palabra "lengua” (siendo esta la más precisa para su correcta interpretación).

Todavía más, se ha llegado a pensar que esa clase de comunicación (animal), no merece siquiera ser reconocida como forma de comunicación, sino que en realidad debería denominarse como contagio, tal y como plantea Lev Vygotsky (1934) en su obra Pensamiento y Lenguaje.

El pensamiento de Vygotsky es ampliamente compartido, sin embargo, existen también autores como
Jean Jacques Rousseau (1781), el cual plantea que: "No me cabe la menor duda de que los animales que trabajan y viven en comunidad, los castores, las hormigas, las abejas, tienen una lengua natural para comunicarse entre sí” (p.25). Para Rousseau, las lenguas eran todas aquellas formas por medio de las cuales se comunicaban las especies, lo que corresponde (en gran parte) a nuestra definición de manifestación lingüística. Por esto, en el contexto que se ha venido desarrollando, la lengua deberá ser entendida como manifestación lingüística. La tesis esbozada ha sido la más contrariada en pro de la exclusividad comunicativa de la especie humana, que bien sea a través del lenguaje o a través de la comunicación pretende hacer mella en la línea que separa y diferencia a los seres humanos de los otros miembros del gran reino animal.

De esta manera, se podría afirmar que hay dos grandes bandos en relación con la validez o no de las formas de comunicación no humanas, siendo el primero el más dominante. Ahora, lo cierto es que existe un factor en el que coinciden ambos grupos, cuál es el lenguaje, toda vez que, tanto los que niegan la comunicación animal como aquellos que la validan, defienden la idea (en la mayoría de los casos) de que el lenguaje es único, a saber, propio de la especie humana y de nadie (¿̇o nada?) más.

Esta idea, desde la perspectiva del presente artículo, no tiene el más mínimo sentido, puesto que, el lenguaje y la comunicación se encuentran unidos inescindiblemente. En tal sentido, si hay comunicación hay lenguaje, en la medida que, la comunicación desde su aspecto interno es concebida como aquel producto formado por los elementos del lenguaje.

Por lo anterior, es válido afirmar que quien se comunica es un poseedor del lenguaje, y como "es evidente que los animales son capaces de comunicarse a cierto nivel entre sí, así como con los humanos" (Gleason, 2010, p. 9), estos (los animales) son, por consiguiente, legítimos poseedores del lenguaje.

\section{OBJETIVOS}

El presente artículo pretende analizar las caracte- 
rísticas esenciales del lenguaje con el fin de extender su concepto y aplicación a los animales no humanos, de manera que, se logre atenuar la sinécdoque existente en la epistemología del lenguaje y de la lengua. Lo anterior, permitirá que la clásica concepción del lenguaje sea aplicada más allá de los límites impuestos por la doctrina mayoritaria, lo cual se traduce en que los animales no humanos puedan ser considerados como poseedores del lenguaje.

\section{METODOLOGÍA}

El presente artículo de reflexión se encuadra dentro del tipo de investigación cualitativa según el abordaje del problema, por cuanto se enfoca en la esencia del objeto investigativo. En ese sentido y a partir del nivel de profundidad, lainvestigación es explicativa, correlativa y propositiva, toda vez que, se pretenden sustentar teóricamente las razones por las cuales existen confusiones conceptuales en torno al lenguaje; se busca establecer la relación entre lenguaje, lengua y pensamiento en aras de identificar las diferencias entre los mismos $\mathrm{y}$; se propone una nueva manera de entender el lenguaje desde su más amplia definición, esto es, extendiendo su aplicación a los animales no humanos. Así pues, el área de investigación en la que se circunscribe este artículo corresponde a la filosofía del lenguaje.

En ese orden de ideas, el método utilizado es el deductivo-analítico en la medida en que se aborda la investigación desde el marco general del lenguaje hasta sus componentes más particulares, a saber: elementos, interacciones y funciones del mismo. Además, se opta por dividir lógica y estructuralmente al objeto de estudio, tomando como fundamento las debilidades teóricas que fungen como base para hacer frente al paradigma lingüístico contemporáneo.

Por lo anterior, es necesaria la implementación de técnicas de recolección de información con el propósito de describir el estado actual de la teoría del lenguaje y contrastar tal información con los presupuestos teóricos fruto de la investigación. De ahí que, se emplee el estudio y análisis documental de textos científicos, tales como libros y artículos académicos, para arribar a las posturas y conclusiones que se persiguen con el presente artículo de reflexión.

\section{CONCLUSIONES}

El lenguaje ha sido el centro de innumerables estudios desde los prolegómenos de la historia. La construcción técnica y social de la epistemología del lenguaje se ha establecido de manera distinta a través de sus muchos teóricos. Sin embargo, existe un común denominador con respecto al concepto y alcance del mismo: su carácter exclusivo. Frente a dicha exclusividad, se han expuesto diversas razones con el fin de resaltar que es el ser humano el único capaz de poseer el lenguaje.

En ese sentido, la tesis principal que se ha tratado de defender en el presente trabajo ha estado encaminada al desarrollo de lo que se considera como una confusión conceptual y, por tanto, un restringido campo de aplicación del lenguaje. El binomio capacidad-elemento ha permitido entender al lenguaje desde una perspectiva más amplia, de modo que, los demás animales de la tierra puedan ser considerados como poseedores. La carencia de una lengua y la incapacidad de utilizar el pensamiento han sido las principales razones por las cuales a los animales se les ha excluido de todo estudio relativo al lenguaje.

Con respecto a lo anterior, se explica en primera instancia que la lengua sólo es una parte del lenguaje, específicamente, de las manifestaciones lingüísticas. Esta última es una especie del lenguaje que tiene por sí misma muchas formas, dentro de las que se encuentran también las señales químicas, visuales, táctiles y auditivas, propias de los animales no humanos. Por lo que, se logra evidenciar que la lengua no es siquiera la única forma de manifestación lingüística existente. De esta manera, no puede (como se ha hecho hasta el momento) ser tratada como el lenguaje, pues este es el género de los géneros y no una especie de las especies.

Ahora, la idea anterior permite, además, llegar a la conclusión de que, si el lenguaje no es una especie de las especies, mucho menos puede ser considerado un 
producto de alguna de ellas. En tal sentido, se explica la relación del pensamiento con la lengua: cómo la lengua se conforma esencialmente de pensamiento y cómo el pensamiento se expresa y se reproduce a partir de la lengua. Punto que, ayuda a entender que el lenguaje no se relaciona directamente con el pensamiento y que, por tanto, pensar no es un requisito para ser considerado un poseedor del lenguaje. Así entonces, los animales no humanos aun cuando no tienen pensamiento, sí son poseedores del lenguaje.

De todo lo explicado, también se debe resaltar que la ejecución de acciones que solo pueden realizarse a través del lenguaje, permite reconocer a quién (¿o qué?) es o no un poseedor del mismo. De esta forma, la representación y comunicación que generan los otros animales de la tierra, muestran cómo ellos pese a no ser homo, y mucho menos sapiens, sí pueden ser poseedores y sobre todo del lenguaje. Más aún, cuando este con su existencia lo que pretende es unir y no separar, como sí lo ha hecho a largo de la historia esta pequeña-gran especie.

Por todo lo dicho, es menester cambiar la concepción que se tiene en relación con el lenguaje; comprender que la diferencia está en el color y no el ojo, a saber: en la lenguay en el pensamiento, pero no en el lenguaje, que como se ha reiterado, no pertenece exclusivamente a los miembros de una especie que intenta comprender el mundo, pero que a veces olvida que el universo es un tanto más grande.

\section{Referencias}

Barón, L. \& Müller, O. (2014). La Teoría Lingüística de Noam Chomsky: del Inicio a la Actualidad. Revista Lenguaje 42(2). 417-442.

Gadamer, H. (1960). Verdady método. Ediciones Sígueme.

Gleason, J. B. (2010). El desarrollo del lenguaje. (Moreno, Y. 7 Ed.) Pearson.

Llinás, R. (2017). El cerebro y el mito del yo: el papel de las neuronas en el pensamiento y el comportamiento humano. El peregrino.

Piaget, J. (1977). El lenguaje y el pensamiento en el niño. Guadalupe.

Rousseau, J. J. (2008). Ensayo sobre el origen de las lenguas. (Vera, D. \& Poyrazian, M. Trad.). Editorial Universidad Nacional de Córdoba. Encuentro Grupo Editor. (Trabajo original publicado en 1781).

Sánchez, J. C. (1921). Nuevo Concepto del Diccionario Español de la Lengua. Real Academia Española.

Saussure, F. (1945). Curso de lingüística general. Losada.

Tijeras, E. (1965). La frase de Protágoras en nuestro tiempo. Ediciones Mundo Hispánico.

Trillos, J. J. (2017). Del lenguaje y la comunicación. Corporación Universidad de la Costa.

Vygotsky, L. (1934). Pensamiento y Lenguaje. Grupo Planeta.

Whorf, B. L. (1956). Lenguaje, pensamiento y realidad. Barral.

Wittgenstein, L. (1921). Tractatus lógico filosófico. Alianza. 